\title{
Zur Fortpflanzung der Konjugaten
}

Von

\section{Seikan Kusunoki}

(Aus dem Botanischen Institut der Himezi-Kôtôgakkô, Himezi, Nippon)

(Mit 112 Figuren)

Eingegangen am 20. Januar $19 / 4$

Inhaltsverzeichnis

Einleitung

I. Untersuchungen über die Fortpflanzung von Konjugaten

a. Closterium Lunula

b. Closterium pusillum HAUTSCH, var. monolithum WitTr.

c. Zygnema sp., Mougeotia sp.

II. Zytologische Untersuchungen über abnormale Kopulation und andere Erscheinungen bei Konjugaten. (Closterium Lunula)

III. Untersuchungen über besondere amöboide Zustände von Zoosporen. (Basicladia crassa und andere)

IV. Über Fadenzerfall und Verjüngung. (Draparnaldia plumosa (Vauch.) Ag.)

:(Bd. 14)

V. Ergebnis

VI. Zusammenfassung

VII. Literaturverzeichnis

\section{Einleitung}

Die Fortpflanzung der Konjugaten bietet der Forschung viele Probleme. Und welches davon man auch angreifen mag - immer stößt man letztlich auf Fragen, die sich der Beantwortung entziehen. Ich habe mich mehrere Jahre lang mit verschiedenen solchen Problemen beschäftigt und mein Interesse besonders den Erscheinungen zugewandt, die einen beträchtlichen Unterschied zwischen Konjugaten und anderen Chlorophyzeen offenbaren. Das sind vor allem:

1. Verschiedene Kopulationstypen und deren Beziehungen zueinander.

2. Amöboide Zustände von Gameten.

3. Nicht nur bei Konjugaten sondern auch an anderen Chlorophyzeen zu beobachtende Erscheinungen, wie Fadenzerfall u.a.

Zur Untersuchung der unter 1. genannten Erscheinungen wurden Closterium, Zygnema und Mougeotia benutzt. Bei Closterium Lunula wurden außerdem über die Bedeutung der Vakuolen, die Beziehung der 
verschiedenen Plasmabestandteile zueinander und anderes Untersuchungen angestellt und ich bin dabei zu neuen Ergebnissen gekommen.

Für die Untersuchung von Problem 2 habe ich an einer anderen Chlorophyzee, Basicladia crassa über die verschiedenen Stadien amöboider Zustände von Zoosporen Untersuchungen angestellt und dabei verschiedene Einblicke in das Wesen des amöboiden Charakters der Geschlechtszellen gewomnen.

Was Problem 3 betrifft, so kann man unter den Konjugaten Fadenzerfall besonders oft bei Zygnema, Spirogyra u.a. beobachten. Ich habe. jedoch an einer anderen Chlorophyzee, Draparnaldia plumosa (VAUCH.) $\mathrm{Ag}$., Einblick in das Wesen des Fadenzerfalls gewinnen können.

Auf Grund der genannten Untersuchungen konnte ich auch das phylogenetische Problem der Konjugaten berühren und nebenher konnten auch verschiedene andere interessante Probleme gestreift werden.

Natürlich konnten auch meine Untersuchungen keine fundamentale Lösung der genannten schwierigen Probleme erbringen, aber ich bin doch davon überzeugt, daß durch sie wenigstens verschiedene neue Gesichtspunkt gewonnen wurden.

\section{Untersuchungen über die Fortpflanzung von Konjugaten}

(a. Closterium Lunula. b. Closterium pusillum HAUTSCH var. monolithum WitTr. c. Zygnema sp., Mougeotia sp.)

\section{a. Closterium Lunula}

Schon Morren (Morren, 1836) und De Bary (De Bary, 1858) habere jn ihrer ersten wichtigen Arbeit über Closterium Lunula erkannt, daß sich zwei Zygoten bilden und auch der bekannte Algologe Oltmanns (1922) hat darüber berichtet. Aber die von ihm übernommenen Figuren Morrens und DE BARYs stellen abnorme Typen dar, die Reihenfolge der Figuren scheint nicht zu stimmen und eine Figur ist zu primitiv. Deshalb wurde deren im übrigen vorzügliche Arbeit von vielen Autoren nicht sehr oder nicht genug beachtet und sie hielten sich stattdessen an die unbefriedigenden Arbeiten von RALFs (über Closterium lineatum EHRENB.), von West u. Fritsch (West u. Fritsch, 1927) und Okamura (OKamura, 1930). Auch SMith hat in seinem Buche nicht nur die Figuren von MorRen und DE. BARYs nicht beachtet, sondern auch deren genaue Untersuchungen ganzlich übersehen.

Was die Figuren von RALFS betrifft, so stimme ich mit SMITH ${ }^{11}$ ziemlich

1 SмITH, G.M., 1483. S. 568. "other species with a conjugation of juyenile cells, asPenium didymocarpum Lund, have a pair of cells bloming opposed to another pair and a production of twin zygotes within the common gelatinous envelope. It is not clear whether the twin zygotes characteristic of Celosterium lineatum EHRENB. and $\mathrm{Cl}$. Ralfii var hybrium. RAB. are formed in this monner, or by a division of the protoplast to form two gametes." 
larin überein, daß es, da an den Austrittsstellen des Protoplasmas keine Tortsätze zu sehen sind, wahrscheinlich ist, daß die beiden Closterien sich $\mathrm{n}$ der Mitte geteilt und eine Zygote gebildet haben, die sich nachher in 2 eille.

Ich möchte zunächst auf die Beobachtungen von MORREN und DE BARY singehen und dann über meine eigenen weiteren Beobachtungen berichten.

Nach MORREN und DE BARY lagen zunächst viele Closterien unregelnäßig zerstreut. Zur Kopulationszeit legten sie sich, die Konkavseiten sinander zugekehrt, paarweise zusammen. Sie trennten sich dann am sthmus und bildeten 4 Halbzellen. An der Trennungsstelle erfuhren diese uun einen gewissen Zuwachs mit stumpferer Spitze als am anderen Pol. An der neugebildeten Spitze bildete sich ein Vakuolenkristall wie der an ler gegenüberliegenden Spitze bereits vorhandene und an den Innenseiten ler Zuwachsteile bildeten sich Fortsätze, aus denen das Protoplasma der je 2 gegenüberliegenden Halbzellen austrat und sich unter Bildung je einer Zygote, also insgesamt zweier, vereinigte. Diese großen Zygoten verzleinerten sich dann und blieben bis zur Keimung latent (Fig. 1-4).

Ich konnte nun beobachten, daß manchmal von den beiden paarweise relagerten Closterien sich nur eines mit darauffolgendem Zuwachs der sebildeten Hälften teilte, während das andere unverändert blieb. Die seiden Halbzellen wanderten dann ab und jede suchte sich einen neuen ungeteilten Paarungspartner (Fig. 5, 7). Diesem gegenübergelagert teilten sie sich vor dem Vollzug der Kopulation nach dem inzwischen sebildeten, dem stumpfen $\mathrm{Pol}$ näher liegenden Isthmus in eine größere und zine kleinere Hälfte, so daß je zwei Hälften und je zwei Viertel der ursprünglichen Zellen einander gegenüberlagen. Das größere Viertel hatte dieselbe Form, wie die Teilungshälften der ursprünglichen Zelle und war nur kleiner als diese, die andere, durch Zuwachs ergänzte Hälfte dagegen hatte auch andere Gestalt (Fig. 6). (Da die betreffende Photographie undeutlich ausfiel, habe ich mich auf die Wiedergabe dieser schematischen Zeichnung beschränkt). Im Gegensatz nur normalen Lage des Kopulationspaares zeigt Fig. 7 eine abnorme Lagerung. Auch hier wandern Viertelszellen zu neuer Kopulation mit Zellhälften ab. Fig. 8, 9 zeigen zine solche Wanderung einer Viertellszelle. Es ist zu vermuten, daß auch die kleineren Viertelszellen, nachdem sie sich von ihren größeren Hälften setrennt haben, Kopulationen mit anderen Viertelszellen, denen sie besegnen, eingehen, wenn auch solche Kopulationen bis jetzt nicht beobachtet werden konnten.

In manchen Fallen ist bei Closterium auch triploide Konjugation $\mathrm{zu}$ Jeobachten, indem zwei Zellhälften normal kopulieren, während die dritte in einer anderen öffnung einer der beiden Zellen konjugiert. In solchen Fällen kommt es jedoch an keiner der Kopulationsstellen zu richtiger Zygotenbildung. Triploidie ist also unfruchtbar. 
Nun habe ich diesmal in einem einzigen Falle bei diesem Closterium einen neuen Kopulationstyp beobachtet, den ich "Terminalkopulation“ nenrien möchte (Fig. 10). Die beiden Closterienhälften die, die spitzen
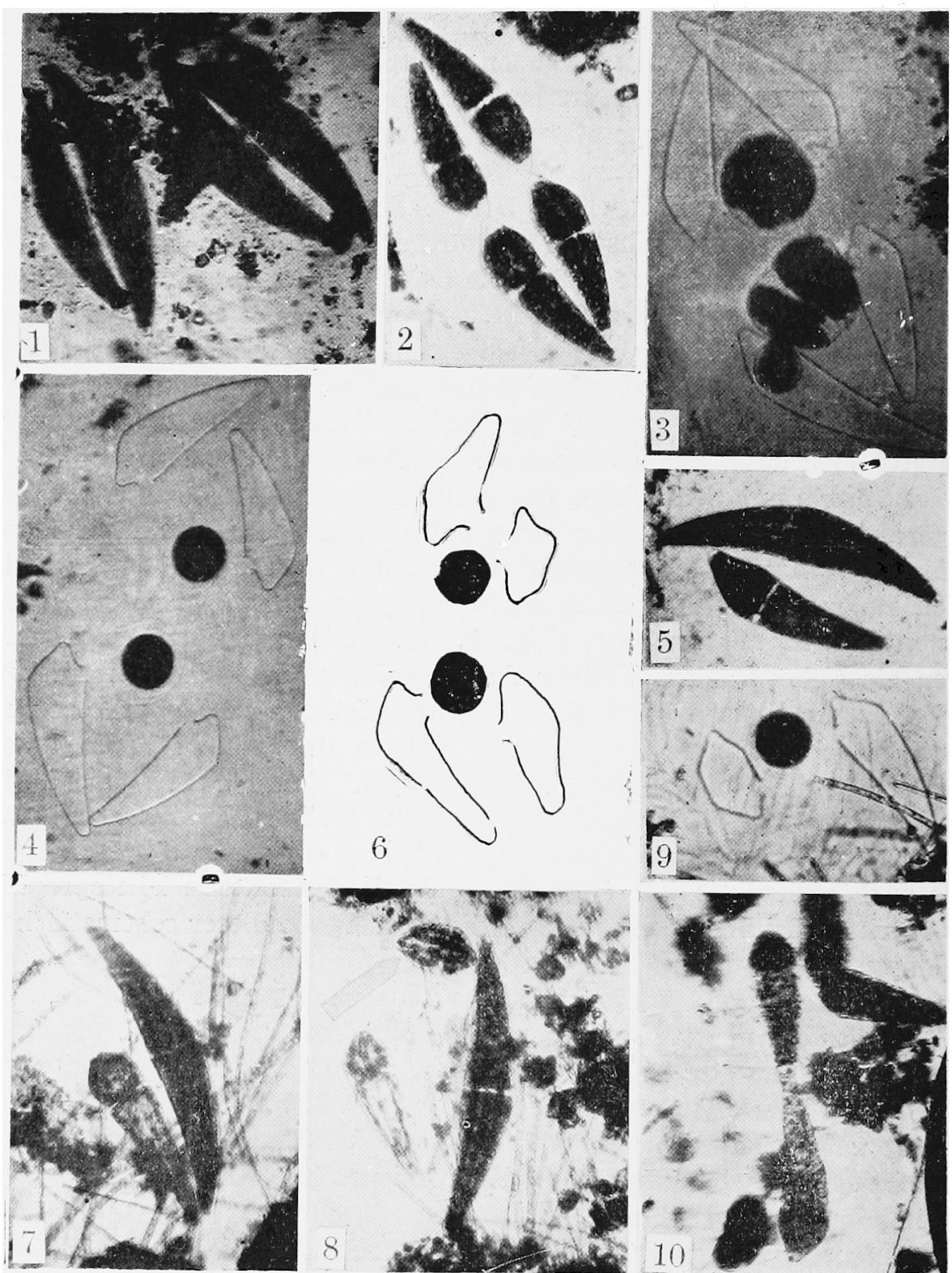

6
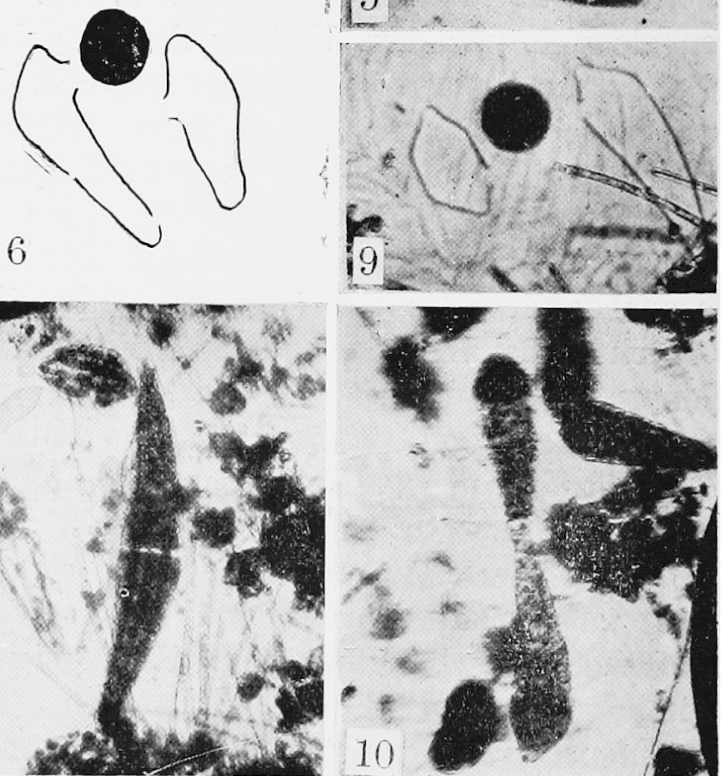

Fig. 1-10. Closterium Lunula. 104×. 1-5, 7-10 Photographien. 6 schematische Darstellung.

Enden einander zukehrend, in einer Linie liegen, verschmelzen mit den einander zugekehrten Spitzen, allerdings ohne daß eine Zygotenbildung zustandekommt. 


\section{b. Closterium pusillum HAUTSCH var. monolithum WITTR.}

Im vergangenen Sommer, am 20. Juni 1942 habe ich in Himezi (Mittelnippon) diese Art zum ersten Male gesammelt, und zwar von der Erde feuchter Straßenränder im Hügelland. Sie fand sich in größeren oder kleineren Ansammlungen innerhalb des blaugrünen Oscillatoria-Rasens, der in papierdünner Schicht die Erde überzog. Zunächst konnte ich keine Kopulationsstadien beobachten, aber eine Woche später fand ich in an derselben Stelle gesammeltem Material Kopulationsstadien. Im Anschluß daran konnte ich dann Keimungsstadien beobachten. Aber schon Anfang Juli konnte ich kein frisches Material mehr auftreiben.

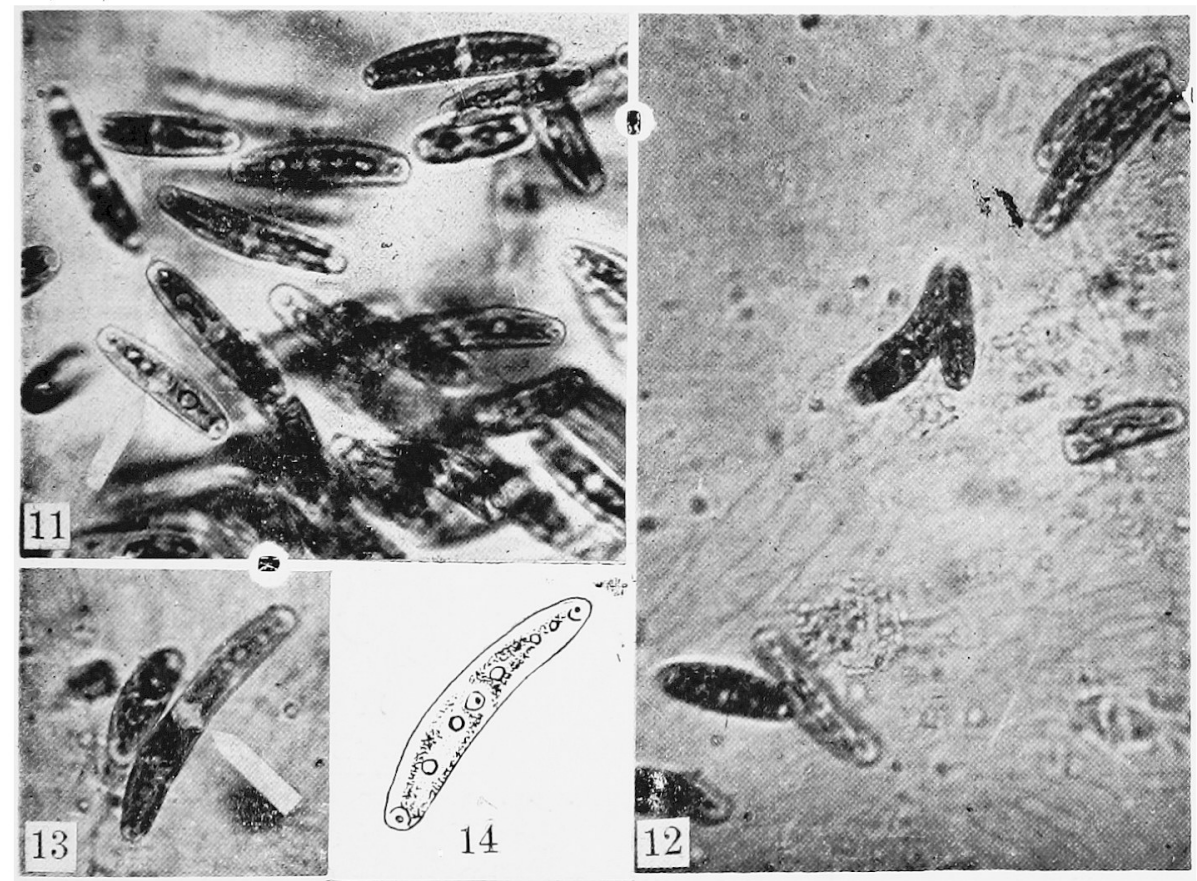

Fig. 11-14. Closterium pusillum HAUTSCH var. monolithum WITTR. 644X.

Die Zygoten dieser 1886 entdeckten Art wurden bis heute nicht beschrieben. Das ist wohl auf die Seltenheit dieser Art zurückzuführen und darauf, daß man sie bei oberflächlicher Betrachtung leicht für eine Oscillatoria-Art halten kann. Es ist ziemlich schwer, solche Zygoten zu finden und deshalb habe ich diesen Sommer oft dieselbe Fundstelle besucht, ohne jedoch nochmals auch nur eine Spur des erwünschten Materials zu finden. Deshalb können die Angaben dieses Kapitels leider nicht Anspruch auf volle Sicherheit erheben.

Fig. 11 zeigt eine Ansammlung von Closterien vor der Kopulationszeit. Die Vakuolen beider Pole enthalten je einen (sehr selten zwei) bewegliche Kristalle. Der Kern befindet sich in der Mitte des zentral 
gelegenen Isthmus. Die Pyrenoide und deren Teilungen sind wie gewöhnlich. Fig. 12 zeigt den Anfang des Kopulationsstadiums. Die Figuren 13 und 14 stellen dasselbe Objekt dar, Fig. 14 schematisch. Fig. 13 zeigt ebenfalls, an einem Paare, das Anfangsstadium der Kopulation. Interessant ist besonders, daß hier die eine Zelle besonders groß ist und statt wie gewöhnlich zwei polare Vakuolen mit je einem beweglichen Kristall noch

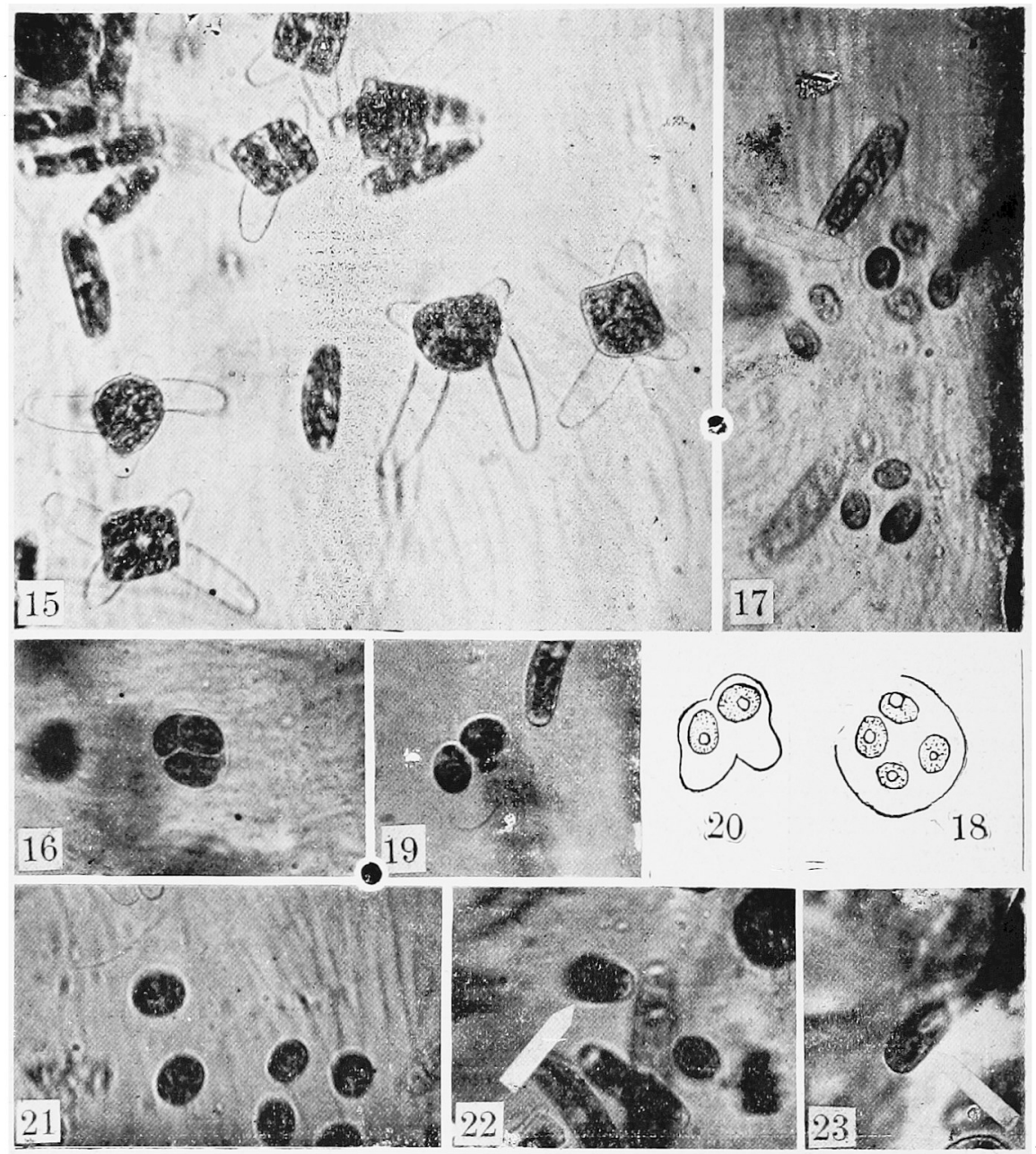

Fig. 15-23. Closterium pusillum HAUTSCH var. monolithum WITTR. 644X. eine dritte zentrale Vakuole mit ebenfalls einem solchen aufweist.

Bei der Erörterung der Ergebnisse von Kapitel II soll im Zusammenhang mit anderen Erscheinungen davon eingehender die Rede sein. Fig. 15 gibt ein fortgeschrittenes Stadium der Kopulation wieder.

Die Figuren 16, 17, 18 (Schem von 17), 19, 20 (Schema von 19) zeigen fortgeschrittene Stadien der Kopulation unter Reifung der Zygoten. Die Figur 21 zeigt sehr wahrscheinlich aus der Zelle ausgetretene ge- 
schlechtliche Elemente, die Figuren 22 und 23 zeigen schließlich deutlich die jungen Closterienformen. Bei den Figuren 21 und 22 scheint es auf den ersten Blick, als wäre nur an je einem Pole eine Vakuole vorhanden, bei näherem Zusehen läßt sich aber auch die des anderen Poles erkennen.

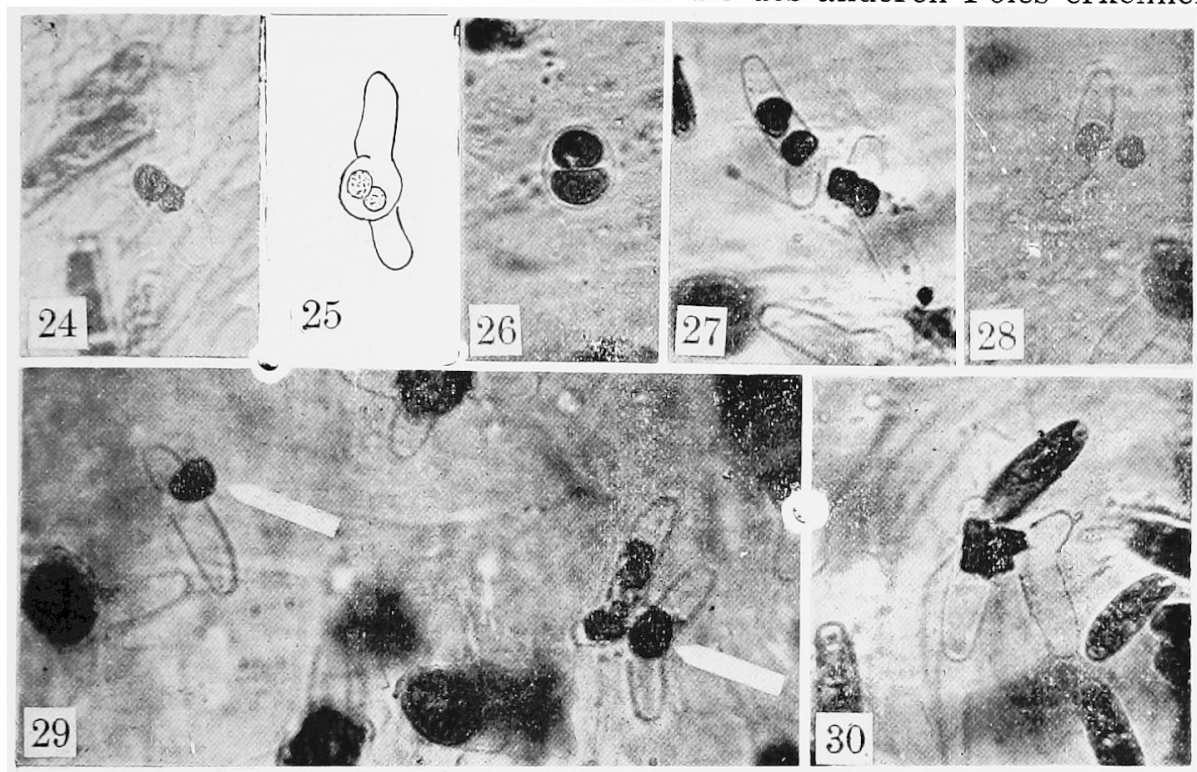

Fig. 24-30. Closterium pusillum HAUTSCH var. monolithum WitTr. $644 \times$.

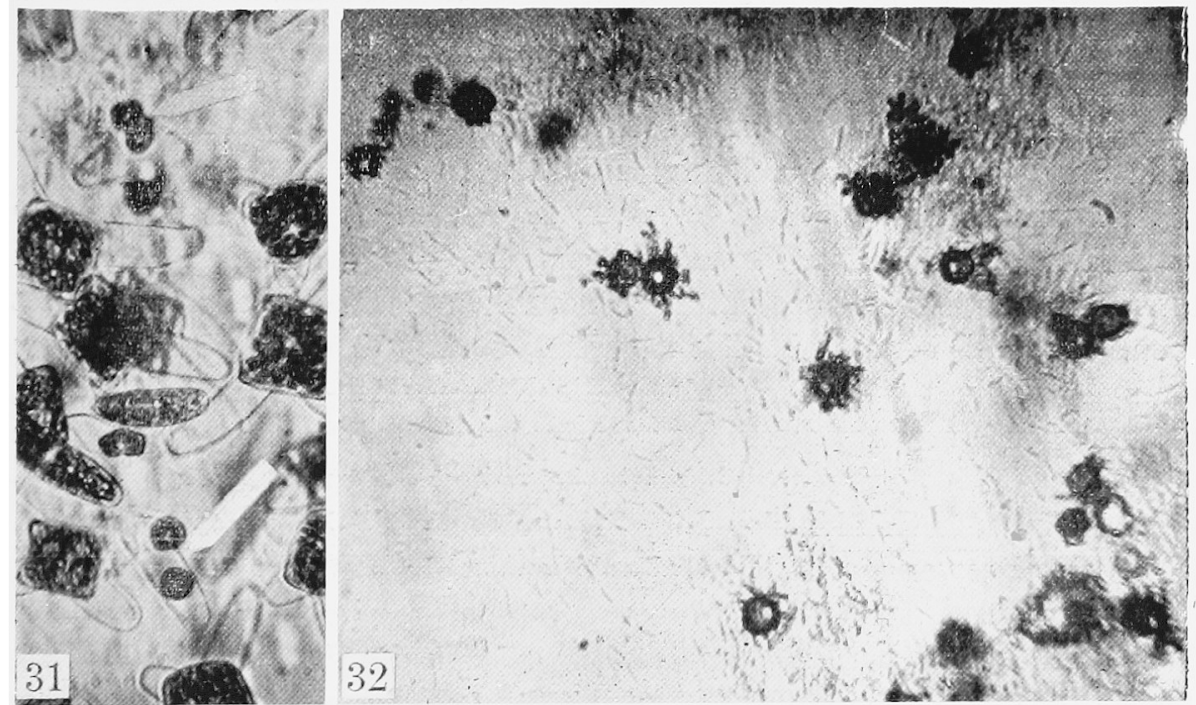

Fig. 31, 32. Closterium pusillum HAUTSCH var. monolithum WITTR. 644X.

Fig. 24, 25 (Schema von 24) und 26 zeigen im Innern zwei (statt 4) geschlechtliche Elemente, wahrscheinlich Azygoten. Die Figuren 27 und 28 zeigen, wie sich inmitten der Kopulation beide Zellen trennen und die geschlechtlichen Elemente nach außen austreten - eine Erscheinung, die 
ich sehr oft beobachtete und die wohl auf Absterben zurückzuführen ist. Fig. 29 zeigt in einigen Zellen nur ein aber dafür größeres geschlechtliches Element, das aber sicher im Absterben begriffen ist. Fig. 30 zeigt bei derselben Art anisogame Kopulation. Auf die phylogenetische Bedeutung dieser Erscheinung will ich bei der Besprechung der Ergebnisse eingehen. Fig. 31: am Rande braun, in der Mitte weiß erscheinende schon abgestorbene geschlechtliche Elemente (in den vorangehenden Fällen war die Farbe immer grün gewesen). Fig. 32 schließlich solche der gleichen Art im ausgetretenen Zustande, wie ich sie massenhaft beobachten konnte. Bei dieser Art habe ich erstmalig — wenn auch aus Materialmangel nicht mit genügender Sicherheit - bewegliche geschlechtliche Elemente beobachten können. Es wurde - ohne näheres Eingehen auf die Erscheinungen — der Wichtigkeit dieser Beobachtung halber wenigstens auf die Möglichkeit dieser bis jetzt unbekannten Tatsache hingewiesen.

Ich habe bei dieser Art vor der Keimung der reifen Zygote einige bewegliche Gebilde gefunden, die ganz den Eindruck von beweglichen geschlechtlichen Elementen machten. Zilien konnten aber daran nicht festgestellt werden - vielleicht weil sie im Schleim des Plasmas, in dem sich die Gebilde befanden, nicht sichtbar wurden (Fig. 17, 18). Einen Austritt dieser beweglichen geschlechtlichen Elemente konnte ich nicht beobachten, aber es ist möglich, daß sie mit den in Fig. 21 abgebildeten, außerhalb der Zellen beobachteten Gebilden identisch sind, die zwei Zilien und einen Augenfleck aufweisen. Die Figuren 22 und 23 zeigen bereits fortgeschrittene Stadien, die den Charakter dieser Art deutlich erkennen lassen - Zwischenglieder zwischen dem Stadium der Fig. 21 und den Stadien der Figuren 22, 23 konnten nicht beobachtet werden.

Bei Desmidiazeen ist man gewohnt, daß die Zygoten erst nach einer längeren Latenzperiode zur Keimung kommen. Aber bei der vorliegenden Art konnte das Keimungsstadium schon nach kurzer Zeit beobachtet werden. Deshalb bezweifelte ich zunächst, ob hier überhaupt bereits ein Keimungsstadium vorliege, aber, wie die Figuren 19-20 deutlich zeigen, handelt es sich hier sicher um einen Fortschritt des Stadium der Fig. 15: ein Teil der geschlechtlichen Elemente ist schon abgewandert und wahrscheinlich sind die Gebilde der Fig. 21, welche mit Zilien versehen sind, mit solchen abgewanderten Elementen identisch. Eine Aufeinanderfolge der frühen Stadien konnte allerdings nicht festgestellt werden, vor allem nicht der Übergang des Stadiums von Fig. 21 in die Stadien der Fig. 22, 23 welche letztere aber wenigstens sicher als Entwicklungsstadien dieser Art zu erkennen sind.

\section{c. Zygnema sp., Mougeotia sp.}

Oberflächlich gesehen scheint die Art der Kopulation der Konjugaten sehr einfach zu sein, aber bei genauerer Beobachtung stellt sie sich als 
sehr kompliziert heraus. Bei Zygnema sp. konnte ich diesmal einen besonders interessanten Kopulationstypus beobachten. Auf grund der Beziehungen zwischen diesen Beobachtungen und den Ergebnissen meiner früheren Beobachtungen an Mougeotia sp., die ebenfalls einen besonderen

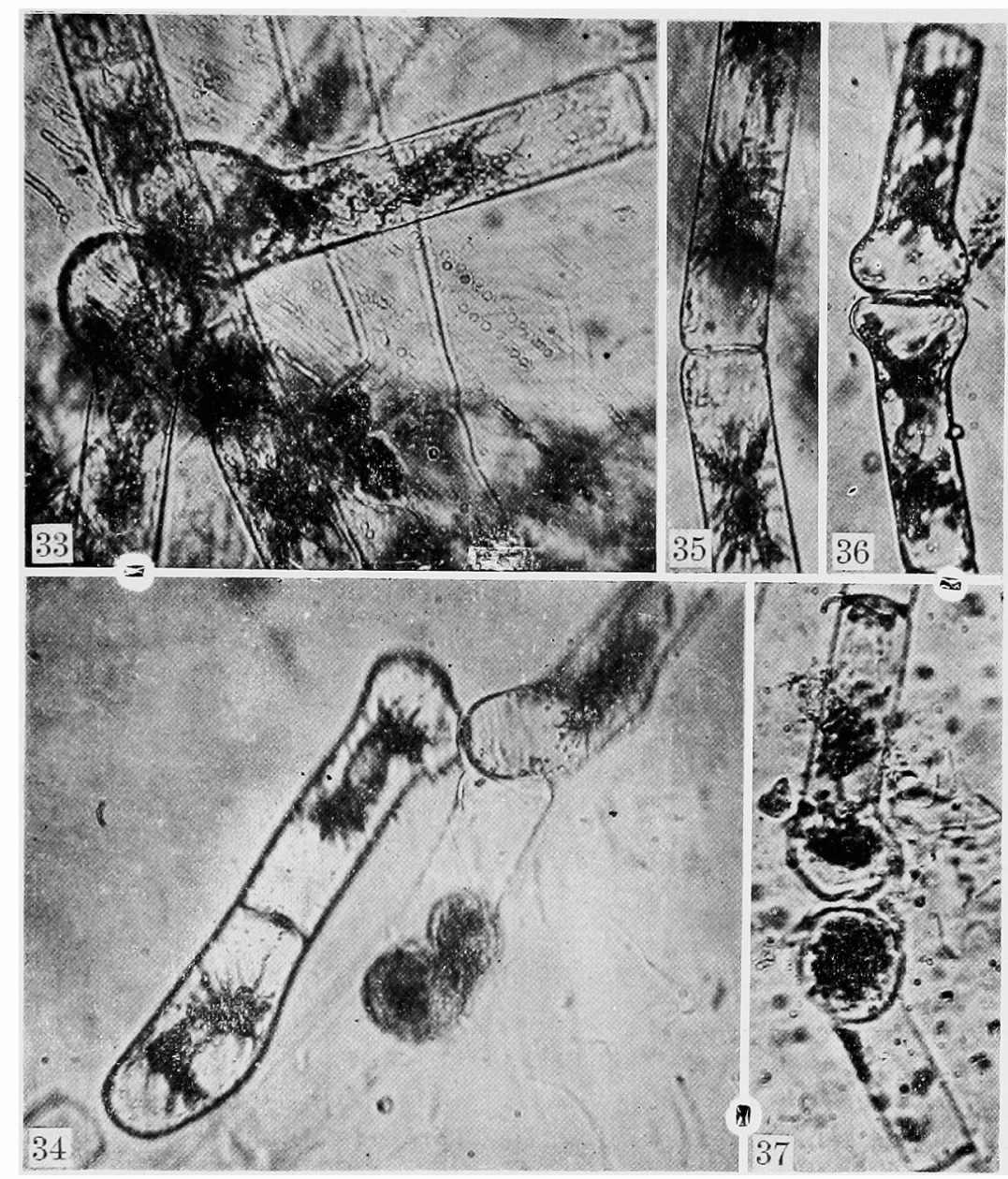

Fig. 33-37. Zygnema sp. $644 \times$.

Kopulationstypus ergaben, bin ich zu einer neuen Auffassung der Terminologie der Kopulationstypen gekommen. $\mathrm{Zu}$ den bisher bekannten Typen der Leiter- und Seitenkopulation füge ich als dritten den Typus der terminalen Kopulation hinzu. Eine strenge Definition erfordert weiter eine Unterteilung dieses Typus in zwei Untergruppen. Da bei Pilzen eine derartige terminale Kopulation häufig zu finden ist, habe ich das phylogenetische Problem berührt. Weiters habe ich über die Beziehungen zwischen Leiter- und Seitenkopulation interessante Kenntnisse gewinnen 
können. Bei der Besprechung der Ergebnisse soll darauf näher eingegangen werden.

Die beiden kopulierenden Zellen in Fig. 33 gehören entweder zwei fremden Fäden an, oder es sind zwei Hälften eines und desselben getrennten Fadens. Auf keinen Fall aber sind sie als Nachbarzellen desselben Fadens anzusehen. Sie repräsentieren den von CzURDA besprochenen Fall einer leiterförmigen Kopulation, die äußerlich wie eine seitliche anzusehen ist. Fig. 34 zeigt einen Fall gewöhnlicher leiterförmiger Kopulation, der sich aber doch etwas dem Fall der Fig. 33 nähert, der ,,besonderen leiterförmigen Kopulation“ CzURDAs. Fig. 35-37 zeigen auch jenen ,besonderen

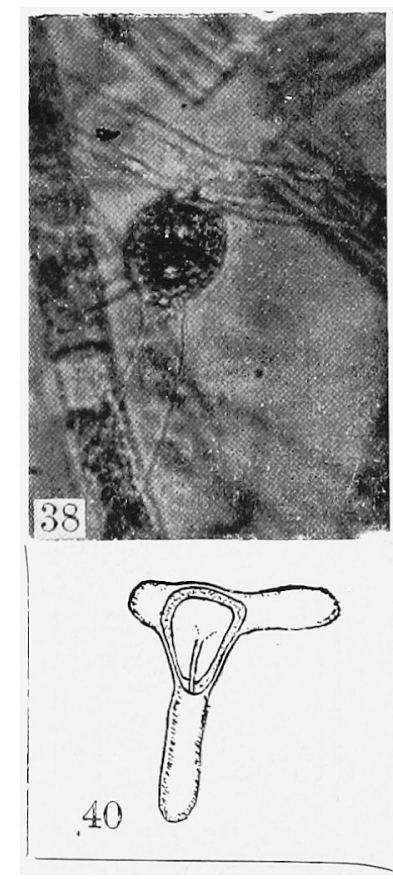

Fig. 38, 39. Mougeotia sp. $644 \times$.

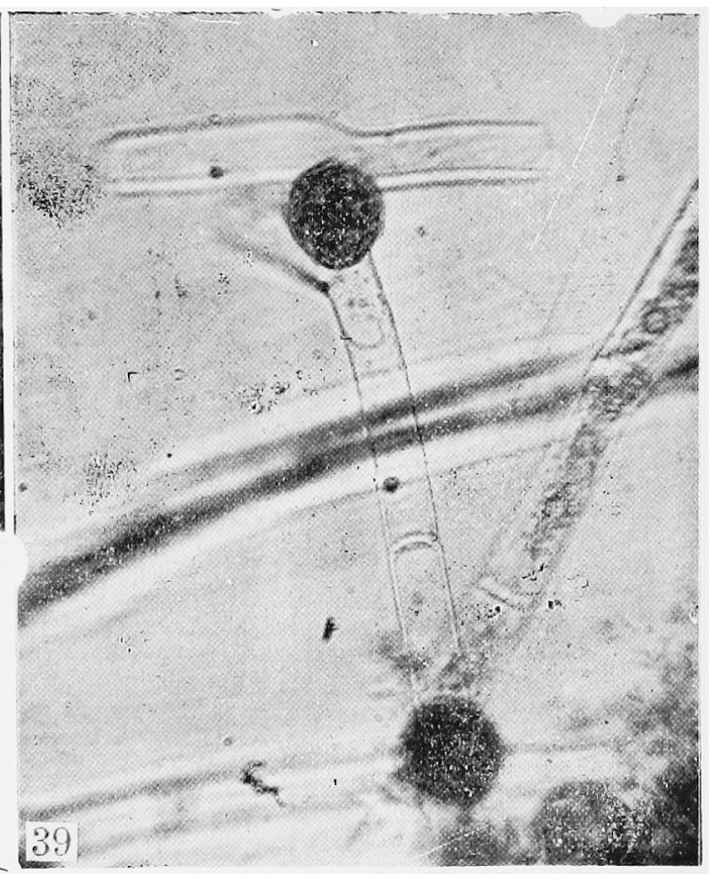

Fig. 40. M. Taylori aus CzURdA.

Fall von Leiter kopulation" Czurdas, der aus einem vor der Kopulation erfolgenden Fadenzerfall zu erklären ist, infolge dessen zwei ursprünglich benachbarte Zellen prinzipiell wie die Zellen zweier fremder Fäden in Kopulation treten. Die verschiedenen dargestellten Stadien stellen übrigens nicht ein und dasselbe Objekt dar, sondern waren nebeneinander zu beobachten.

Fig. 35 zeigt ein Stadium unmittelbar vor der Lockerung des Zellzusammenhangs. Fig. 36 dürfte die nach der Lockerung des Zusammenhangs zustandergekommene völlige Wiedervereinigung durch Kopulation darstellen. Fig. 37 stellt einen Fall dar, in dem die Trennung der beiden Zellen vor der Kopulation eine vollständige gewesen war. Fig. 38 wurde 
früher bei Mougeotia sp. aufgenommen und stellt eine besonders interessante Art der Kopulation dar. Fig. 39 zeigt eine bei Mougeotia sp. oft zu beobachtende Erscheinung. Fig. 40 zeigt Mougeotia Taylori aus CzURDA (1928). Fig. 38-40 möchte ich bei der Besprechung der Ergebnisse erklären.

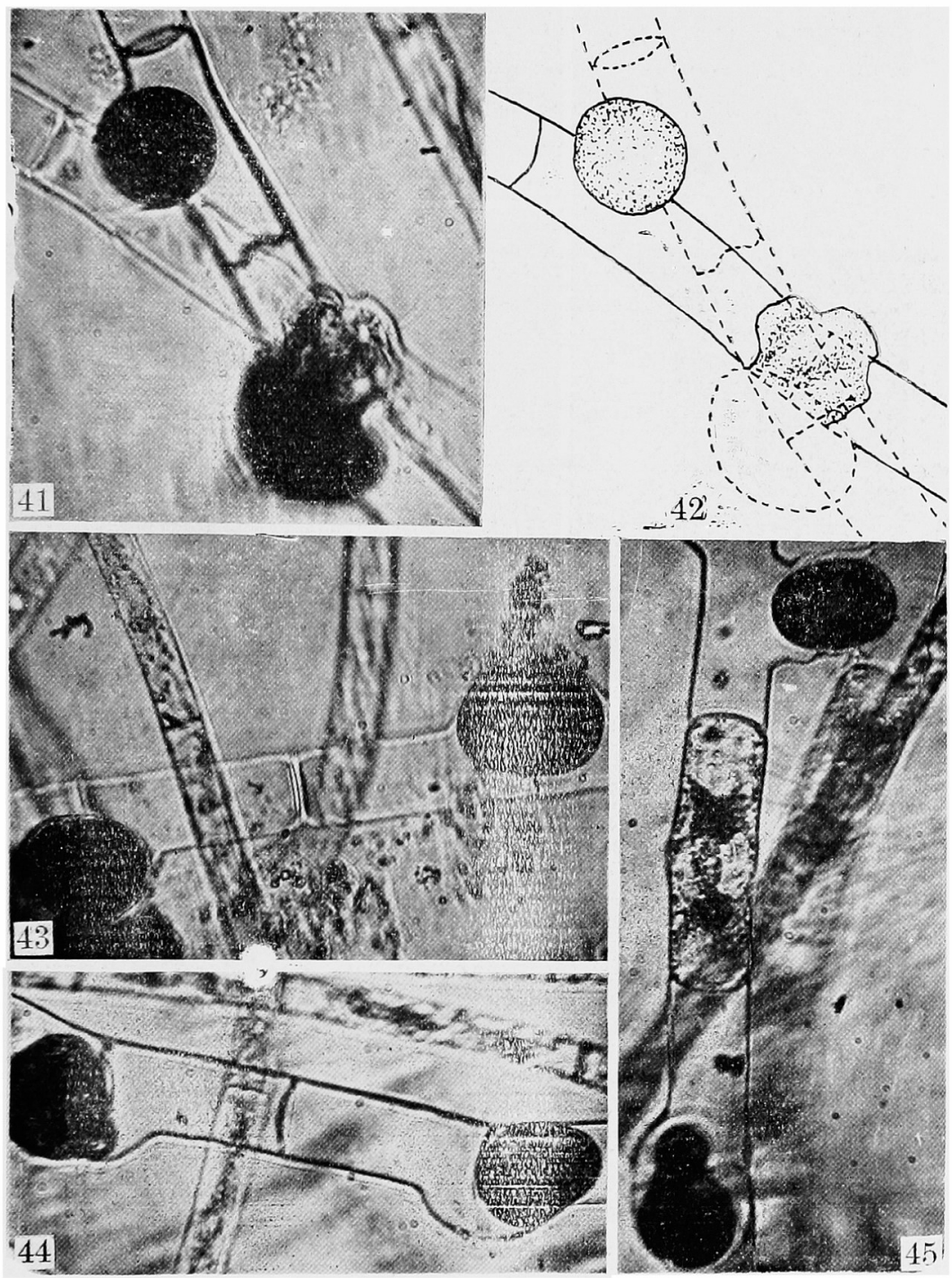

Fig. 41-45. Zygnema sp. $644 \times$. F.s. 42. Schema von Fig. 41 .

Außer den vorher genannten Arten seltner abnormaler Kopulation wurden bei dem beschriebenen Forseh. smaterial (Zygnema sp.) auch die gewöhnlichen normalen Kopulationserscheinungen beobachtet (Fig. 43-49). Diese Figuren sind zum besseren Verständnis der Fig. 41, 42 und 50 aufgenommen worden. Fig. 43 zeigt isogame, Fig. 44 anisogame 
Seitenkopulation. Die Figuren 46-49 zeigen Azygoten. Die Figuren 41 und 42 stellen dasselbe Objekt dar, Fig. 42 schematisch. Die Fig. 41 und 42 zeigen sehr schön die Beziehungen zwischen Seiten- und Leiterkopulation, weshalb ich ihnen besondere Bedeutung beimesse. Auch ihre genauere

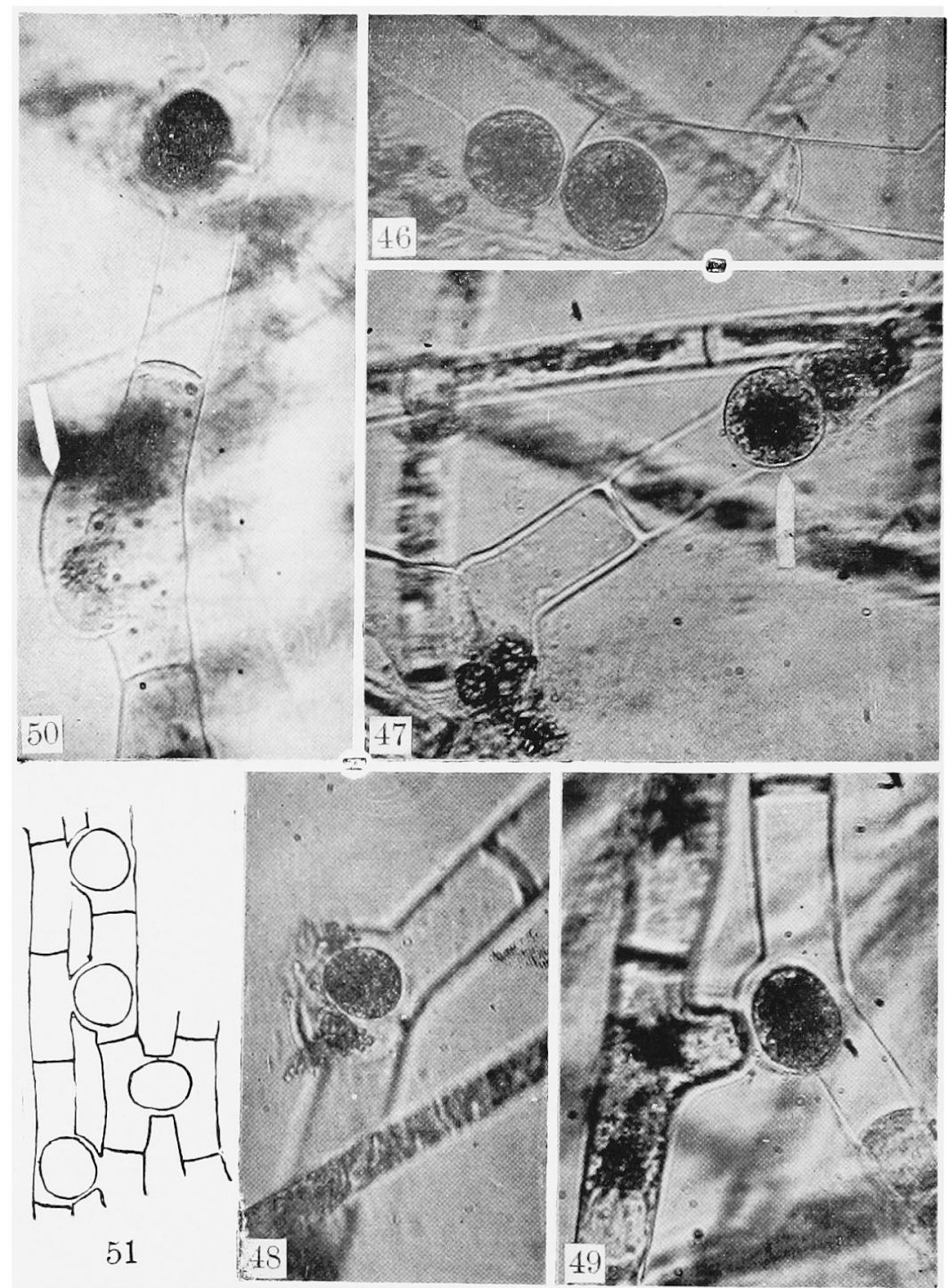

Fig. 46-50. Zygnema sp. $\times 644 . \quad$ Fig. 51. Zygnema callinsianum. nach TraNSEAU.

Erklärung soll bei der Besprechung der Ergebnisse folgen. Fig. 50 zeigt unten eine Azygote, deren Form der einer durch Seitenkopulation entstandenen Zygote auffallend gleicht.

Es wäre noch viel im einzelnen zu zeigen und zu erklären. Hier kam es mir nur darauf an, auf die Vielfalt die Probleme hinzuweisen, die noch 
der Klärung bedürfen. Die Fig. 51 habe ich zur Veranschaulichung der Beziehungen zwischen isogamer und anisogamer Kopulation wiedergegeben.

Bei der Besprechung des Ergebnisses wird die genauere Erklärung dazu gegeben werden.

Zuletzt möchte ich noch darauf hinweisen, daß alle hier beschriebenen Zygnemen der gleichen Art angehören. Vielleicht handelt es sich dabei um eine neue, bis jetzt nicht bekannte Zygnema-Art. Da diese Frage nicht in diesen Zusammenhang gehört, möchte ich jedoch nicht näher darauf eingehen.

\section{Zytologische Untersuchungen über abnormale Kopulation und andere Erscheinungen bei Konjugaten \\ (Closterium Lunula)}

Unter der Bezeichnung ,Terminalkopulation“ habe ich bei Closterizm Lumula eine abnorme Art der Kopulation zweiter Zellhälften beschrieben, die so selten ist, daß sie in der Literatur bis jetzt keine Erwähnung gefunden hat (Kapitel I, Fig. 10). Ich habe die seltene Gelegenheit, die sich mir bot, benützt, um an der Kopulationsstelle verschiedene zytologische Beobachtungen vorzunehmen. Dabei konnten neue Erkenntnisse über den Zweck der Vakuolen und des Isthmus, sowie deren Beziehungen zueinander und $\mathrm{zu}$ den Chloroplasten und der Protoplasmaströmung gewonnen werden.

Die Beobachtungen wurden an einem lebenden Objekt angestellt das in der übrigen zeit in der Feuchtkammer aufbewahrt wurde. Um einen Verlust des wertvollen Materials zu vermeiden, verzichtete ich auf eine Übertragung auf einen ausgehöhlten Objektträger und zog es vor, es in der Umgebung, in der ich es entdeckte, auf einem gewöhnlichen Objektträger, wenn auch unter unnatürlichem Druck, zu beobachten. Um Irrtümer auszuschließen, wurde bei der Übertragung des Präparates in die Feuchtkammer, bzw. aus der Feuchtkammer auf den Objekttisch, eine Drehung oder sonstige Lageänderung desselben sorgfältig vermieden.

Im Laufe der fast einen Monat lang fortgesetzten Beobachtung (das Objekt blieb 28 Tage lang lebendig) bildete sich um dasselbe herum allmählich eine Schleimhülle, welche schließlich Bewegungen desselben verhinderte und so die Beobachtung sehr erleichterts (Untersuchung 1).

Einige Tage nach Beginn der ebengenannten Beobachtungen hatte sich rechts neben die obere der beiden kopulierenden Zellhälften eine weitere parallelgelegt, welche, wohl infolge eines von dieser ausgehenden geschlechtlichen Reizes, vom stumpfen Ende aus einen kurzen Fortsatz gegen diese zu treiben begann. Auch an dieser Zellhälfte, welche bis zum 35 Tage nach Beginn der Beobachtung des Gesammtmaterials am Leben 
blieb, stellte ich weitere Beobachtungen an (Untersuchung 2).

Im gleichen Präparat machte ich schließlich noch an wieder anderen Zellhälften Beobachtungen über den Isthmus. (Im Zusammenhang damit ist von besonderem Interesse, daß im Falle der Untersuchung 1 sich an der Kopulationsstelle allmählich ein neuer Isthmus herauszubilden begann.) Dieses Material blieb vom Anfang der Gesammtbeobachtung an 32 Tage am Leben (Untersuchung 3).

Über den Zweck der Vakuolen von Closterium und auch noch über anciere an Closterium sp. vorgenommene Beobachtungen ist im Kapitel I die Rede. Das Material ging während der Beobachtungszeit allmählich zugrunde und wenn auch nicht immer, so ließ sich doch in vielen Fällen die Lebensdauer ziemlich genau feststellen. Der Stichtag für den Beginn aller Beobachtungen ist der 24. Mai 1942.

\section{Untersuchung 1 .}

1. Tag. $^{1}$ (Fig. 52,58). Bei der Terminalkopulation lassen sich deutlich eine passive obere und eine aktive untere Hälfte unterscheiden. Die Zellwand an der Spitze der passiven Fälfte ist bereits verschwunden und die Spitze der aktiven Hälfte dringt in die so entstandene offnung ein. Die normalerweise in den Vakuolen der spitzen Pole befindlichen Vakuolenkristalle ${ }^{2}$ sind zwar auf der Photographie nicht zu erkennen, sie konnten jedoch unter dem Mikroskop beobachtet werden. Dabei waren sie in der unteren aktiven Hälfte (Fig. 58a), deutlicher zu erkennen, als in der oberen passiven (Fig. 58b). Am sturnpfen Pol sind Vakuolenkristalle nur bei der aktiven Hälfte zu beobachten.

Istmusbildung ist noch bei keiner der beiden Zellhälften zu sehen.

4. Tag (Fig. 53, 59). Jetzt ist auch die Zellwand der aktiven Spitze verschwunden. Die Vakuolenkristalle am spitzen Pol der aktiven Hälfte (Fig. 58a) sind viel deutlicher und zahlreicher geworden, die Vakuolenkristalle im spitzen Pol der passiven Hälfte dagegen sind nicht nur undeutlicher sondern auch weniger geworden. Die Fig. 53 und 59 stellen dar, wie unterhalb von a von Fig. 58 die Bildung eines neuen Isthmus einsetzt.

6. Tag. (Fig. 54, 60). Der neuentstandene Isthmus zwischen den beicien kopulierenden Zellhälften ist noch viel deutlicher geworden und die in Fig. 53 und 59 oberhalb desselben befindlichen Valuolenkristalle finden sich nun im Isthmus selbst (Fig. 60a), b von Fig. 59 hat sich soweit

1 1., 4., 6., u.s.w. Tag bedeutet: der soundsovielte Tag seit dem Beginn der Beobachtung; also die Länge der Kulturdauer.

... an den Zellenden je eine Vakuole mit winzigen in Bewegung befindlichen Gipskristallen aufweist." (Strasburgar S. 337). Der Einfachheit halber gebrauche ich im folgenden statt ,, Vakuolen mit Gipskristallen" meist einfach den Ausdruck ,, Vakuolenkristalle." 
vermindert, daß es gerade an der Grenze der Feststellbarkeit angelangt ist (Fig. 60b). Angesichts der gleichzeitigen Vergrößerung von a ist wohl die Annahme berechtigt, daß die Vakuolenkristalle von b zum größten Teil nach a gewandert sind und dort cie Vermehrung und Vergrößerung hervorgerufen haben.
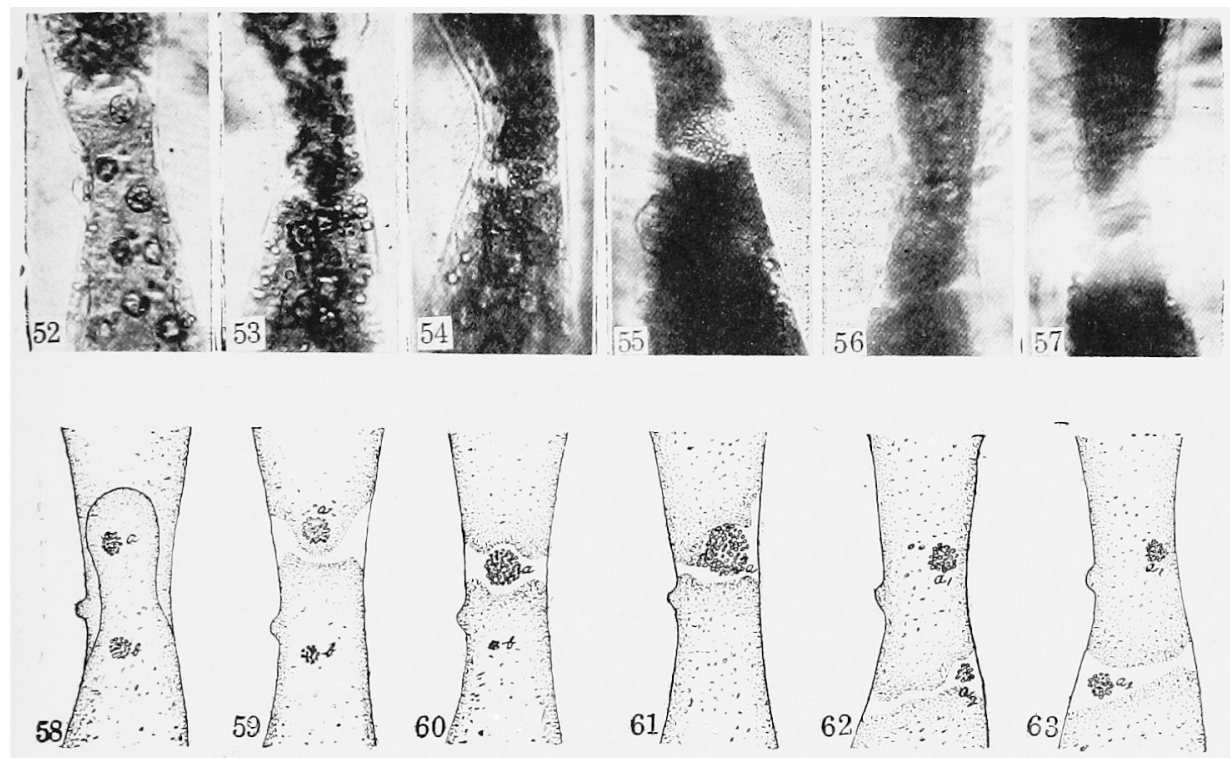

Fig. 52-57. Closterium Lunula. 368 $\times$ 58-63. Schematische Darstellung vom Fig. 52-57 in derselben Reihenfolge.

7. Tag. (Fig. 64). Jetzt erst ist auch an den stumpfen Polen beider Hälften die Isthmusbildung deutlich geworden. Die vor einigen Tagen im stumpfen Ende des passiven Teils gebildeten Vakuolenkristalle, die infolge der Bedeckung mit Chloroplasten nicht recht sichtbar gewesen waren, sind jetzt deutlich geworden und beide Zellhälften, die früher nach einer geraden Achse orientiert waren, erscheinen jetzt leicht gegeneinander nach links gebogen. Außerdem haben sie auch etwas an Größe zugenommen. Die ebenbeschriebenen Tatsachen sind deutlich zu erkennen, wenn man die Fig. 10 des Kapitel I und die Fig. 64 dieses Kapitels miteinander vergleicht. Die Vakuolenkristalle sind allerdings infolge der geringen Vergrößerung nicht sichtbar.

11. Tag. (Fig. 55 u. 61). A von Fig. 60 erscheint bedeutend vermehrt und der Isthmus erheblich auf der rechten Seite verbreitert.

21. Tag. (Fig. 56 u. 62). Der in Fig. 55 u. 61 deutlich sichtbare Isthmus ist völlig verschwunden — die ihm entsprechende Gegend ist gänzlich mit Chloroplasten bedeckt. Siattdessen ist etwas unterhalb davon ein schmaler neuer Isthmus sichtbar geworden. Anstelle des einen Vakuolen- 
kristallhaufens der Fig. 55 u. 61 sind nun wieder zwei sichtbar geworden (Fig. 62a $a_{1} u_{2} a_{2}$ ) von denen der obere, etwas größere, sich etwas rechts vonı ursprünglichen Orte befindet, während der untere, etwas kleinere rechts im neuen Isthmus liegt. Beide erscheinen also nach rechts verlagert.

24. Tag. Der eine der beiden am 21. Tage beobachteten Vakuolenkristallhaufen, $a_{2}$, der am 24. Tage morgens 8 Uhr noch deutlich $z u$ sehen gewesen war, ließ sich nachmittags um 5 Uhr am selben Tage, also 9 Stunden später, nicht mehr auffinden, so dicht war seine Stelle um diese Zeit mit Chloroplasten bedeckt. Auch der andere Haufen $a_{1}$ zeigte sich nun mit Chloroplasten bedeckt, aber nicht so sehr, als daß er dadurch unsichtbar geworden wäre.

25. Tag. Die Vakuolenkristalle $\mathrm{a}_{2}$, die am Vortage morgens noch auf der rechten Seite des Isthmus sichtbar gewesen und am Abend unter der Chloroplastenmasse verschwunden waren, erscheinen nun am Morgen des 25. Tages, nur mehr teilweise von Chloroplasten verhüllt, im Zentrum des Isthmus.

96. Tag. (Fig. 57, 63). Die am Morgen des Vortags wieder sichtbar gewesenen Vakuolenkristalle $a_{2}$ sind an die linke Seite des Isthmus gerückt und, von aller Chloroplastenverhüllung frei, völlig sichtbar. Die Bewegung der Vakuolenkristalle, die sich dem Auge als eine Wanderung vom rechten Ende des Isthmus zum linken darstellt, vollzog sich also binnen mehr als 40 Stunden. Wie bisher zeigt sich auch hier der Isthmus an der Stelle, an der sich die Vakuolenkristalle befinden, verbreitert (d.h. die Chloroplasten sina dort zurïckgewichen). Es konnte beobachtet werden, wie die Verbreiterung in 4 Stunden um $5 \mu$ fortschritt. Dabei zeigte sich eine ziemlich lebhafte flimmernde Bewegung der Vakuolenkristalle.

28. Tag. Beide Zellhälften haben nun ihr Protoplasma entleert. Die Austrittsstelle läßt sich an der rechten Seite der passiven Zellhälfte erkenneı. Bemerkenswert ist dabei, daß der Austritt an jener öfter erwähnten Stelle erfolgte, auf die durch eine parallel danebengelagerte dritte Zellhälfte ein geschlechtlicher Reiz ausgeübt worden war.

\section{Untersuchung 2 .}

7. Tag. (Fig. 64). Die der passiven Zellhälfte parallel gelagerte dritte Zellhäifte, die auf die vorgenannte einen geschlechtlichen Reiz ausübt, soll im folgenden a-Zellhälfte genannt werden. Ich vermute, daß die Anlagerung dieser a-Zellhälfte einige Tage vorher erfolgt war. Infolge des ungewöhnliches Falles, daß sich die andere Zellhälfte bereits in Terminalkopulation befand, bildet sich jedoch an der Reizstelle der in Terminalkopulation befindlichen Zello kein Kopulationsfortsatz, wie er von der die Reizun; ausübenden a-Zellhälfte geoildet worden war. Aus der Tatsache jedoch, daß später der Austritt des gesamten Plasmas der beiden in Ter- 
minalkopulation befindlichen Zellen an dieser Stelle erfolgte, ist zu schließen, daß die Reizung immerhin gewisse, zunächst nicht in die Erscheinung tretende innere Veränderungen zur Folge gahabt hat.

11. Tag. Um die Entwicklung des Fortsatzes der a-Zellhälfte weiter zu verfolgen, fügte ich dem Präparat einige Tropfen $0.1 \%$ ige KNoPsche Lösung zu.

12. Tag. Infolge des Zusatzes der KNoPsche Lösung ist der Fortsatz der a-Zellhälfte ziemlich zuruckgegangen, jedoch immer noch als eine Art Anschwellung erkennber.

14. Tag. Von dem Fortsatz ist auch keine Spur von der Art der am 12. Tage zu beobachtenden Anschwellung mehr zu erkennen. Die Einwirkung der $0.1 \%$ igen KNOPschen Lösung hat also den Fortsatz binnen knapp 4 Tagen völlig zum Verschwinden gebracht.

21. Tag. Der verschwunden gewesene Auswuchs der a-Zellhälfte ist wieder an der gleichen Stelle wie vorher in Erscheinung getreten.

23. Tag. Der Gipskristallhaufen in der Vakuole am stumpfen Ende der a-Zellhälfte ist derart mit Chloroplasten bedeckt, daß er fast unsichtbar geworden ist. Am spitzen Pol ist überhaupt keine Vakuole zu sehen und dementsprechend sind auch keine Vakuolenkristalle zu erkennen. In der Gegend des spitzen Poles ist die Protoplasmaströmung ziemlich heftig, was mir als eine Art Ausgleich für das Verschwinden der Vakuole erseheint. Um den schon zweimal in Erscheinung getretenen Fortsatz wieder zum Verschwinden $z u$ bringen, setzte ich von diesem Tage ab 4 Tag lang, also im ganzen viermal, 0.1\%ige KNoPsche Lösung zu.

24 Tag. Die in der Gegend des spitzen Poles der a-Zellhälfte befindlichen Chloroplasten haben sich tiefer in die Zelle zurückgezogen und in dem freier gewordenen Gebiet ist die Protoplasmaströmung heftiger geworden. Im Gegensatz dazu ist die Vakuole am stumpfen Pol zwar mit Chloroplasten überladen, aber sicher erknnbar. Dort ist jedoch die Protoplasmaströmung nur gering.

28. Tag. In der a-Zellhälfte ist die Vakuole des stumpfen Poles endlich verschwunden, die Protoplasmaströmung ist jedoch immer noch schwach. Die Protoplasmaströmung am spitzen Pol dagegen ist noch viel heftiger geworden. Die Geschwindigkeit der heftiger gewordenen Protoplasmaströmung am spitzen Pol beträgt 5-9 $\mu$ sec. Dieser große Unterschied in der Stärke der Protoplasmaströmung an beiden Polen ist sehr bemerkenswert. Außer den sonstigen zytoplasmatischen Granula fanden sich hier im Bereiche der starken Protoplasmaströmung auch größere Körperchen, wahrscheinlich Vakuolenkristalle beigemischt. Schließlich sind also die Vakuolen beider Pole verschwunden und der in der a-Zellhälfte zum zweiten Male hervorgetretene Fortsatz ist, nach 4maligem Zusatz von $0.1 \%$ iger KNOPscher Lösung, endlich am 6. Tage wieder verchwunden. 
34. Tag. In der a-Zellhälfte ist der Fortsatz an derselben Stelle ein drittes Mal zum Vorschein gekommen und der grosse Gegensatz in der Intensität der Protoplasmaströmung beider Pole besteht noch immer fort.

35. Tag. Die a-Zellhälfte ist nun abgestorben. Bemerkenswert waren besonders das wiederholte Auftreten und Verschwinden des Fortsatzes und die Beziehung zwischen Protoplasmaströmung und Vakuolen, sowie Vakuolen und Chloroplasten, auf die mir durch die geschilderten Beobachtungen ein interessanter Hinweis gegeben zu sein scheint. Die Zelle ist noch 12 Tage nach dem Verschwinden der Vakuole am spitzen und 7 Tage nach deren Verschwinden am stumpfen Pol am Leben gewesen. Sie hat also das Verschwinden der Vakuolen beider Pole noch um 7 Tage überlebt. Da die Chloroplasten am spitzen Pole sich sehr vermindert hatten, war dort das Verschwinden der Vakuole sehr sicher zu erkennen, dagegen ist infolge der starken Verhüllung durch Chloroplasten der Zeitpunkt des Verschwindens der. Vakuole des stumpfen Poles nicht so sicher anzugeben.

\section{Untersuchung 3 .}

21. Tag. Mit diesem Tage wurde eine neue, in der Nähe der in Terminalkopulation befindlichen Zellhälften vorhandene Zellhälfte als Beobachtungsobjekt gewählt. Ich nenne sie im folgenden b-Zellhälfte. Die Vakuole am spitzen Pol derselben ist normal, die am stumpfen Pol dagegen ist zwar als solche zu erkennen, nicht jedoch die völlig mit Chloroplasten bedeckten Vakuolenkristalle. Auch aus anderen Anzeichen ist zu erkennen, daß sich diese b-Zellhälfte bereits in geschwächtem Zustand befindet.

27. Tag. Die Gipskristalle der Vakuole am stumpfen Pol der b-Zellhälfte sind zwar sichtbar, weisen jedoch keinerlei Bewegung auf. Die Vakuole am spitzen Pol weist gegenüber der vorangehenden Beobachtung keine Veränderung auf.

28. Tag. (Fig. 65). Die b-Zellhälfte ist sonst wie bisher, nur der Isthmus ist breiter geworden, woraus sich ein weiteres Fortschreiten der Schwächung erkennen läßt. (Die halbschematische Darstellung der Fig. 65 zeigt nur diesen Isthmus.)

29. Tag. (Fig. 66). Die linke Seite des Isthmus der b-Zellhälfte ist völiig mit Chloroplasten verhüllt. Die Verhüllung schreitet von links nach rechts weiter fort.

30. Tag. (Fig. 67). Der Isthmus ist nun völlig mit Chloroplasten verhüllt. Dann wird am gleichen Tage etwas unterhalb der Stelle des bisherigen Isthmus ein neuer viel schmälerer Isthmus sichtbar. Solcher Wechsel in der Lage des Isthmus wurde schon unter Untersuchung 1 beschrieben. Die Erscheinung dürfte sehr bemerkenswert sein.

31. Tag. (Fig. 68). Im Gegensatz zur Beobachtung des 29. Tages hat sich, diesmal von rechts her beginnend und nach links fortschreitend, ein 
neuer sehr breiter Isthmus gebildet, dessen Breite ungefähr durch eine dem oberen Rand des ersten breiten und eine den unteren Rand des zweiten, schmalen Isthmus entsprechende Linie gegeben ist. Die Vakuolenkristalle am stumpfen Ende sind noch immer unbeweglich, die am spitzen Pole weisen nur sehr geringe Bewegung auf.

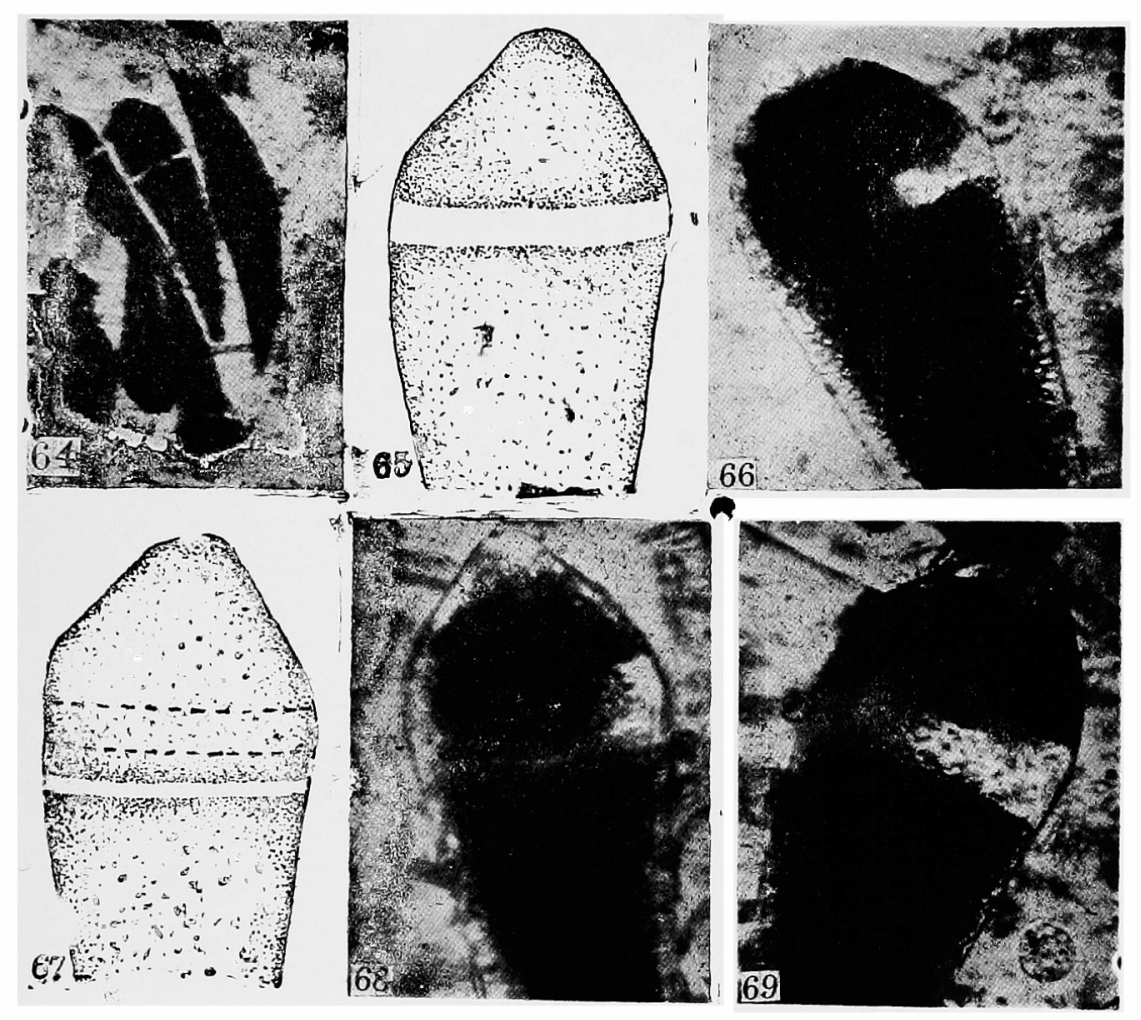

Fig. 64-69. Closterium Lunula. 64, 104×; 65-69.424× 65, 67, schematische Darstellung.

92. Tag. (Fig. 69). Die Zurückziehung der Chloroplasten und damit die Bildung des neuen dritten Isthmus ist nun vollendet, die Vakuolenkristalle am spitzen $\mathrm{Pol}$ sind nun völlig unbeweglich geworden. Auch aus anderen Anzeichen läßt sich schließen, daß das Objekt nun völlig abgestorben ist.

Bemerkenswert ist besonders, daß bej der Verhüllung des ersten Isthmus die Chloroplasten sich von links nach rechts vorschoben, während sie kei der Bildung des dritten, breiten Isthmus umgekehrt sich von rechts nach links zurückzogen. Interessant ist, daß auch unter Untersuchung 1 ähnliche Erscheinungen der Verlagerung des Isthmus beobachtet wurden. 


\section{I. Untersuchungen über besondere amöboide Zustände von Zoosporen. (Basicladia crassa und andere)}

Über amöboide Stadien der Chromatophoren von Phanerogamen und Algen liegen sehr interessante Berichte vor. Besonders zellpathologisch ist diese Erscheinung interessant. Ihr inneres Wesen ist aber immer noch nicht geklärt. Auch über amöboide Stadien bei Zoosporen und Gameten von Algen und anderen Thallophyten liegen zahlreiche Untersuchungen vor, die ebenfalls das innere Wesen unklar lassen. Nur in phylogenetișcher Beziehung sind bis jetzt einige Erklärungen gelungen. Das Innere des Protoplasmas befindet sich auch unter normalen Lebensbedingungen in einem sehr komplizierten Zustand und entsprechend kompliziert erscheint auch die Oberfläche des Protoplasmas in amöboiden Stadien.

Ich untersuchte Basicladia crassa Hoffmann und Tilden, die 1923 von William E. HofFManN (HoFFmanN u. Josephine, 1930) erstmalig in Minnesota U.S.A. gefunden worden ist und über deren Fortpflanzung nur eine sohr einfache Beschreibung von Zoosporen vorliegt. SMITH (SMITH, 1933, S. 432) schreibt über Basicladia crassa, daß bewegliche Fortpflanzungszellen bis jetzt noch nicht beobachtet worden seien, daß aber das häufige Vorkommen leerer Zellen mit einer kleinen seitlichen öffnung darauf hinweise, daß diese Alge Zoosporen oder Gameten bildet, und daß diese Art nur aus Minnesota bekannt sei. Weitere Untersuchungen über diese Pflanze sind mir nicht bekannt und in Nippon wenigstens habe ich sie im vergangenen Jahre als erster entrleckt. Ich konnte an dieser Pflanze sehr interessante Beobachtungen über amöboide Stadien bei Zoosporen machen, über die bis heute keinerlei Berichte vorliegen.

HOFFMANN gibt bei seiner Beschreibung von Basicladia den Fadendurehmesser mit 50-120 $\mu$ an, mein Material zeigte 46-98 $\mu$. Die Fäden dieser Pflanzen sind unten schmal, mit langen Zellen, oben sind sie breiter und bestehen aus entsprechend kürzeren Zellen. Der Durchmesser der Rhizoide beträgt $25-28 \mu$, die vegetative Fortpflanzung ist bei diesen Rhizoiden außerordentlich lebhaft, aber andererseits ist auch von Frühling bis Herost, über ein halbes Jahr lang bei fast allen Zellen der Fäden mit Ausnahme der Basalzellen, Zoosporenbildung $\mathrm{zu}$ beobachten. Bis zu mehreren Hundert sind dabei die Zoosporen in einer einzigen Zelle zu beobachten. Diese treten sämtlich, wenn sie reif geworden sind, manchmal binnen 2-3 Minuten durch eine öffnung, welche sich in der Spitze eines kurzen Auswuchses bildet, ins Freie; manchmal brauchen sie dazu auch 15-20 Minuten. Unter ungewöhnlichen Bedingungen entleert sich das Zoosporangium nicht auf einmal sondern etappenweise und es dauert lange Zeit bis zur völligen Entleerung. Unter besonders schlechten Bedingungen bleibt ein Rest von 10-15, selten von einer einzigen Zoospore in der Zelle zurück, und zwar weil sich die Austrittsöffnung vorzeitig verstopft hat. 
Solche Stadien sind sełır oft zu beobachten. Die übriggebliebenen Zoosporen bewegen sich im Innern dieser Zellen sehr lebhaft. Figuren 70 und 71 zeigen das Austrittsstadium der Zoosporen, Fig. 71 nach 24stündiger Einwirkung einer $10 \%$ igen Rohrzuckerlösung. Die normalerweise kugeligen Zoosporen haben hier ellipsoidische Gestalt angenommen. Fig. 72 zeigt einige Zellen, in denen die Reife der Zoosporen noch nicht hinreichend fotgeschritten ist. Alle Zellen waren hier zunächst vegetative Zellen gewesen - aber allmählich hatten sie sich, mit Ausnahme der Basalzellen, sämtlich in Zoosporangien verwandelt, deren größerer Teil sich
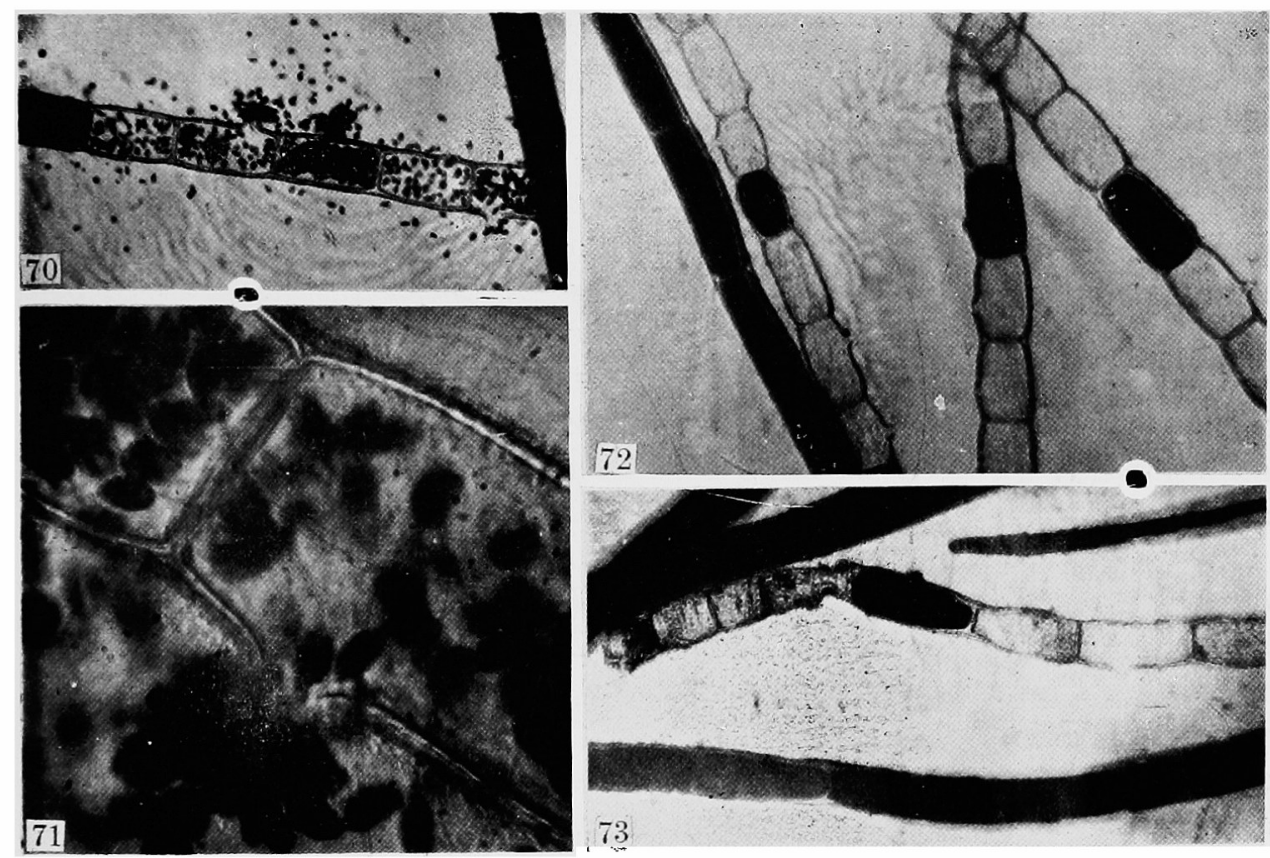

Fig. 7C-73. Basicladia crassa. 70, 72, 73, 78×; 71, 483×.

bereits entleert hatte. Bei den noch nicht entleerten verspäteten Zellen hat sich offenbar der vegetative Charakter länger erhalten, so daß sie sogar noch, wie die Fig. 74 zeigt, zu lebhaftem Längenwachstum fähig sind. Fig. 74 zeigt einen Fall des Wachstum der Spitzenzelle. Aber auch das Wachstum von Zwischenzellen konnte häufig beobachtet werden, wobei die so wachsenden Zellen einfach in ihre leer gewordenen Nachbarzellen hinein und durch diese hindurchwuchsen. Fig. 75 zeigt rechts isoliert eine einzelne solche Zelle, deren oberes Ende deutliches Spitzenwachstum aufweist. Sie gibt ein Bild aus einer Kultur, die 53 Tage in Leitungswasser gehalten worden war. Hier ist auf die sehr interessante Erscheinung der Fig. 73 hinzuweisen: Die eine dunkle Zelle des mittleren Fadens läßt an der Zuspitzung am oberen Ende erkennen, daß sie noch vegetativen Charakter besitzt (auf Grund der Beobachtungen an anderen Zellen ist diese Zu- 
spitzung als der Anfang des Weiterwachsens in die andere Zelle hinein anzusehen). Allerdings scheint es hier mit dieser Zuspitzung allein sein Bewenden zu haben und zu keinem weiteren Wachstum zu kommen, denn, wie an der Bildung des Auswuchses an der linken Seite zu erkennen ist, setzt nun auch hier, wenn auch sehr verspätet, die Umwandlung der Zelle in ein Zoosporangium ein.

Ich habe verschiedene amöboide Stadien von Zoosporen beobachtet im Zusammenhang mit denen mir der vorliegende Fall besonders wichtig erscheint. Besonders ist die Wandlung des Zellinhalts sehr interessant. Vor der Beschreibung der amöboiden Stadien der Zoosporen erscheint mir eine Erklärung der gewöhnlichen Stadien angebracht. Da die Untersuchungen darüber noch nicht abgeschlossen sind, will ich mich auf die Erklärung des Wichtigsten beschränken.

Die Änderung des Charakters dieser Zoosporen konnte bis jetzt bei den Zoosporen anderer Arten nicht beobachtet werden. Es ist dort sehr selten, daß die ausgetretenen Zoosporen bis zu 1 oder 2 Stunden am Leben bleiben - meistens sterben sie sehr schnell nach dem Austreten ab. Bei diesen Zoosporen jedoch konnte bei günstigen Lebensbedingungen eine mehr als 4stündige Lebensdauer beobachtet werden und auch gegen schlechte Lebensbedingungen besitzen sie eine sehr starke Widerstandskraft.

Wie Fig. 76 zeigt, gibt es zwei Arten von Zoosporen, große und kleine, die beide normalerweise kugelig sind. $\mathrm{Da}$ in den weitgehend entleerten Zellen unter 10 bis 15 kleinen keine oder höchstens eine große Zoospore zu finden ist, darf man annehmen, dass die Zahl der großen ganz allgemein wesentlich kleiner als die der kleinen ist. Deshalb sind die kleinen als die allgemeinen anzusehen, deren Größe nur innerhalb geringer Grenzen schwankt. In Fig. 76 links unten ist auch ein Fall der Keimung einer Zocspore an der Außenseite einer Zelle zu beobachten; auch an der innern Zellwand konnten solche Keimungen von in Innern zurückgebliebenen Zoosporen gefunden werden. Manchmal kann man abnorme Zoosporen Wie die in den Figuren 77 und 78 abgebildeten sehen, die aus Art Kopfstück und einer Art Anhang zu bestehen scheinen, wobei jedoch bei der Fortbewegung die "Anhangs"-Spitze sich vorausbewegt. Die großen Zoosporen, wie eine in Fig. 76 abgebildet ist, besitzen immer 4 Zilien, während die viel häufigeren kleineren Zoosporen, deren mehrere ebenfalls in Fig. 76 sichtbar sind, entweder 2 oder 4 Zilien aufweisen. Fig. 87 gibt, etwas schematisiert, Zoosporen der kleineren Art wieder, die sowohl die Schwankungen in der Grösse als auch die Abweichungen in der Gestalt zur Anschauung bringen. Die Zahl der Zilien beträgt im einen Falle 2, in den beiden anderen Fällen je 4. Der Augenfleck ist zwar nicht so deutlich sichtbar wie in der Abbildung, aber immerhin unzweifelhaft erkennbar. Manchmal zeigen die Zoosporen der kleineren Art ein merkwürdiges 
gametenähnliches Verhalten indem sich je zwei einander anlagern und der eine um den anderen in diesem anhaftenden Zustand merkwürdige Krümmungen ausführt, bis sie sich wieder auf einige Zeit trennen und dann wieder vereinigen. Die Gesamtheit dieser Vorgänge einschließlich der Trennungen und Wiedervereinigungen dauert etwas über 30 Minuten. So handelt es sich wahrscheinlich um keine echte Kopulation, wenn diese auch in sehr seltenen Fällen möglich sein mag. Deshalb habe ich in dieser Abhandlung statt „Gameten“ immer den Ausdruck ,Zoosporen“ gebraucht.

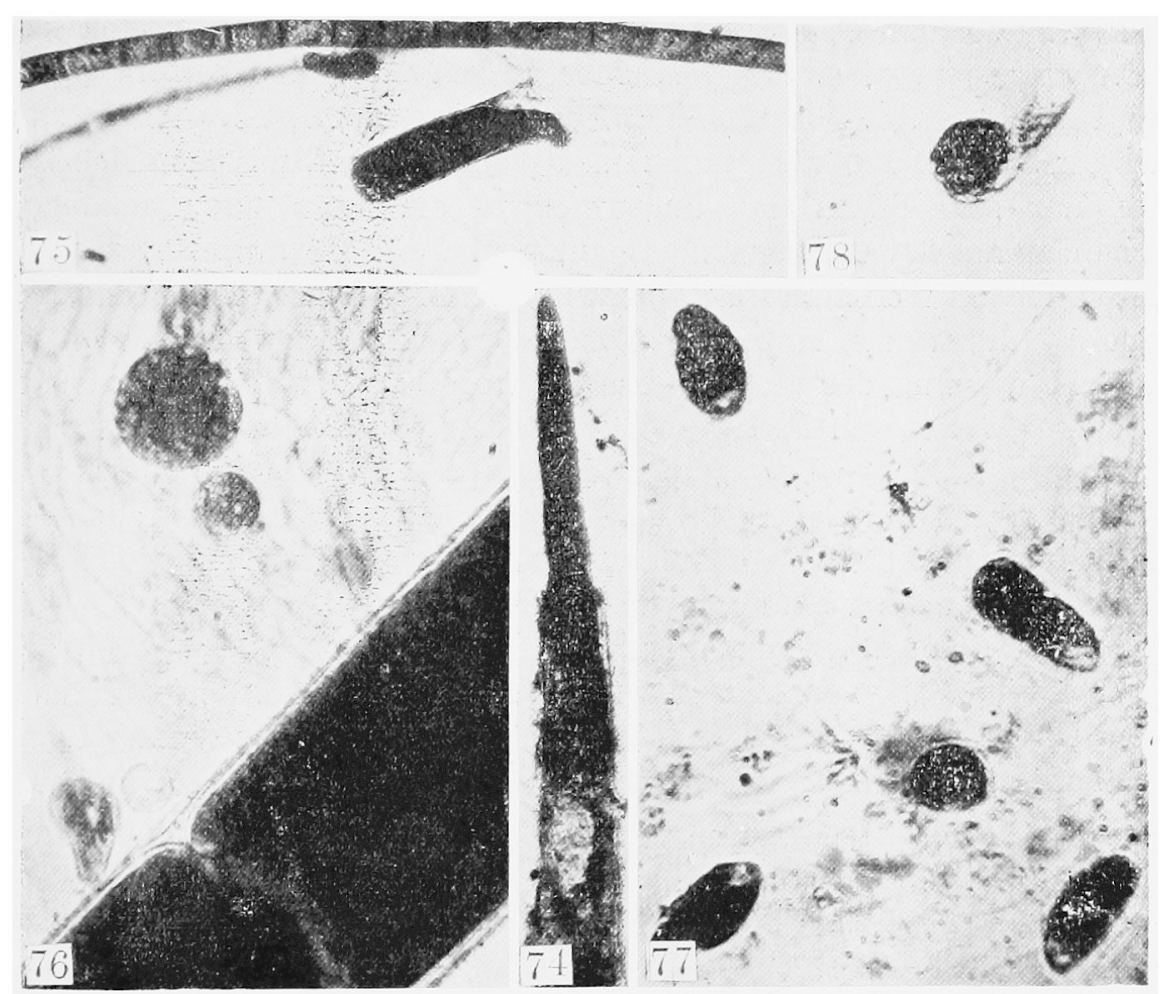

Fig. 74-78. Basicladia crassa. 74, 75, 104× ; 76-78, $644 \times$.

Nun möchte ich meine Beobachtungen über die amöboiden Zustände von Zoosporen schildern. Fig. 79 gibt die Formen einiger Zoosporen wieder, die nach Verschluß der Austrittsöffnung in den Zellen als Rest zurückblieben und heftige amöboide Bewegungen ausführten. Bemerkenswert ist hier besonders noch, daß diese Zoosporen offenbar auf zwei Arten sich bewegen: amöboid einerseits und mittels Zilien andererseits. Wenn die Zilien auch nicht sichtbar sind, solange sich die Zoosporen innerhalb der Zelle befinden, so kann doch wohl aus ihrem sofortigen Sichtbar werden nach dem Austritt aus der Zelle auf ihr schon vorheriges Vorhanden sein geschlossen werden. Weiters ist hervorzuheben, daß diese Erscheinungen nicht unter abnormen Zuständen, sondern in völlig frischen Material 
beobachtet wurden und, wie gesagt, sehr lebhaft waren. Die Bewegungen waren vom Anfang der Beobachtung an noch $13 / 4$ Stunden lang wahrzunehmen, dann erst hörten sie auf und die Form wurde kugelig. Später werden sie dann wohl ins Keimungsstadium eingetreten sein. Bei den gewöhulichen, nicht amöboiden Formen der in der Zelle verbliebenen Zoosporen kann man gewöhnliche, wohl ziliare, Bewegung der kugeligen Gebilde 1-2 Stunden lang beobachten. Fig. 80 zeigt die ebenfalls an frischem Material zufällig entdeckte Erscheinung amöboider Massen, die aus 2-6 amöboiden Gebilden zu bestehen scheinen, die undeutlich gegeneinander abgegrenzt sind. Diese Massen zeigen je eine Anzahl geißelartiger Pseudopodien. Die Massen bilden sich im Moment des Austritts und verlassen zusammenhängend die Austrittsöffnung. Ein Augenfleck ist bei ihnen nur sehr selten und undeutlich zu erkennen; die Pseudopodien erscheinen an der Ansatzstelle manchmal keulenförmig verdickt. Die Massen führen manchaml als Ganzes rotierende Bewegungen aus, wobei kleinere Massen oder einzelne Amöboide passiv mitbewegt werden. Die passive Bewegung der Hauptmasse ist wohl sicher auf Zilien zurückzuführen - die wenigen Pseudopodien würden zur Erzeugung einer derart starken und lebheften Bewegung nicht ausreichen. Manchmal kann man (Fig. 80 unten rechts) auch Zoosporenteilchen beobachten, denen ein langes fadenförmiges Pseudopodium anhaftet. Manchmal haften den Pseudopodien auch weiß Körperchen an, wie an dem Faden am linken Rande der Fig. 80 zu erkennen ist.

In diesem Falle amöboider Massen war die amöboide Bewegung außerordentlich schwach und 15 Minuten nach Beginn der Bewegung kam sie überhaupt zum Stillstand. Allmählich wurde die Form dann undeutlich. Die in den Figuren 79 und 80 abgebildeten Einzelzoosporen und amöboiden Massen waren grün. Bemerkenswert ist, um es nochmals hervorzuheben, die Tatsache, daß die Beobachtungen an ganz frischen Material erfolgten. Die Ursache der Erscheinung ist noch ungeklärt, aber wahrscheinlich ist, daß solche Zusammenballungen entstehen, wenn die Zoosporen in noch unreifem Zustand aus den Zellen austreten.

Der Zusatz von KNoPscher Lösung (BENECKE, 1908) verzögert, der von Rohrzucker (KLEBS, 1896) beschleunigt die Zoosporenbildung. So vermutete ich, daß Rohrzuckerzusa:z auch den Austritt der Zoosporen beschleunigen müße und fand meine Vermutung durch das Experiment bestätigt. Da nach meinen Erfahrungen die Widerstandskraft dieser Pflanzen sehr groß ist, habe ich $10 \%$ ige Rohrzuckerlösung benützt und diese morgens 10 Uhr zugesetzt und 8 Stunden später, abends 6 Uhr, konnte ich schon den Beginn der Entleerung der Zoosporen beobachten, die bis auf einen geringen Rest bereits nach 18 Minuten beendet war. Wie die Fig. 81 zeigt, waren die Formen der ausgetretenen Zoosporen, die von hellgrüner Farbe waren, nicht nur in der Gestalt besonders amöbena- 
ähnlich, sondern die amöboide Gestaltänderung war außerdem ganz besonders lebhaft. Die geißelartigen Pseudopodien, wie sie schon Fig. 80 zeigte, sind hier noch viel länger und manchmal mehrmals spiralig gewunden (Fig. 81 oben rechts). Außerdem wurde unausgesetzt das Verschwinden und Neuentstehen von Pseudopodien beobachtet. Die Vielheit und Lebhaftigkeit all dieser Erscheinungen ergab ein äußerst ansprechendes mikroskopisches Bild. Die weißen, den Fäden anhaftenden IKörperchen, die im Falle der Fig. 80 nicht so häufig waren, traten nun sehr zahlreich auf. Merkwürdigerweise konnten bei den Zoosporen dieser Beobachtung auch nach deren Austritt aus der Zelle keinerlei Zilien beobachtet werden. Die beträchtlichen Größenunterschiede der amöboiden Zoosporen dieses Falles sind vielleicht darauf zurückzuführen, daß infolge der Unreife oder übereilten Reife einige Zellen noch nicht einzeln ausgesondert, sonder im Zusammenhang geblieben waren. 32 Minuten nach Beginn der Beobachtung waren alle amöboiden Erscheinungen, Gestaltänderungen wie amöboide Gestalt überhaupt, verschwunden und die Gebilde hatten unter wesentlicher Verkleinerung ihrer Ausdehnung kugelige Gestalt angenommen. Dann starben sie allmählich ab. Am nächsten Tage nachmittags 4 Uhr, also 30 Stunden nach dem Beginn des Rohrzuckerzusatzes waren neben noch lebendigen auch schon allenthalben abgestorbene Mutterzellen zu beobachten. Manchmal habe ich auch, wie in Fig. 82 gezeigt, merkwürdig gestaltete, ausgetretene, gelbgrüne Zoosporen gefunden unter denen die großeren wahrscheinlich Massen darstellen. Diese bewegten sich mit Zilien und bewegten die kleineren mit Pseudopodien. Die weiße Körperchen sind an ihnen nicht $z u$ beobachten. Am nächsten Abend um 6 Uhr, 56 Stunden nach dem Rohrzuckerzusatz war schon ein großer Teil der Mutterzellen abgestorben und braun geworden. In noch lebenden Zellen ist keine Plasmolyse $\mathrm{zu}$ sehen. Doch konnte man noch ausgetretene amöboide Zoosporenstadien beobachten, wie sie Fig. 83 zeigt. Es fanden sich da sehr lange Pseudopodien mit weißen Körperchen (rechts) oder weiße Fortsätze vom Aussehen der äußeren Schicht von Amö̉en (Mitte) oder zäpfchenförmige Fortsätze mit deutlichem Augenfleck (oben Mitte), wie auch Teilstücke von Zoosporen mit langem Pseudopodium.

Diese Beobachtungen waren ein einmaliger Glücksfall. Ich suchte noch oft durch Rohrzuckerzusatz die beschriebenen Erscheinungen in gleicher Vollkommenheit und Lebendigkeit hervorzurufen, aber alle weiteren Versuche blieben vergeblich. In den meisten Fällen starb das Material schon binnen weniger als 24 Stunden ab. Die nach etwa 4-5 Stunden austretenden Zoosporen zeigten abnorme Zustände. Zilien und Augenfleck waren zu beobachten. 6 Stunden später traten die Pseudopodien in Erscheinung und in der 9 Stunde etwa traten die unreifen Zoosporen als Massen, die aber nicht so typisch, wie die vorher beschriebenen amöboiden 

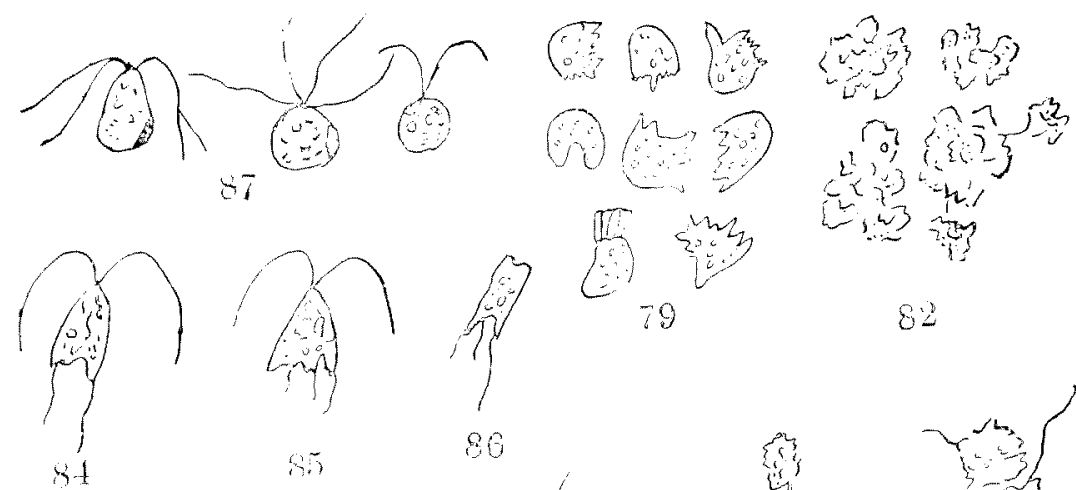

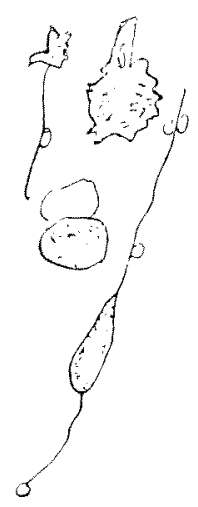

83

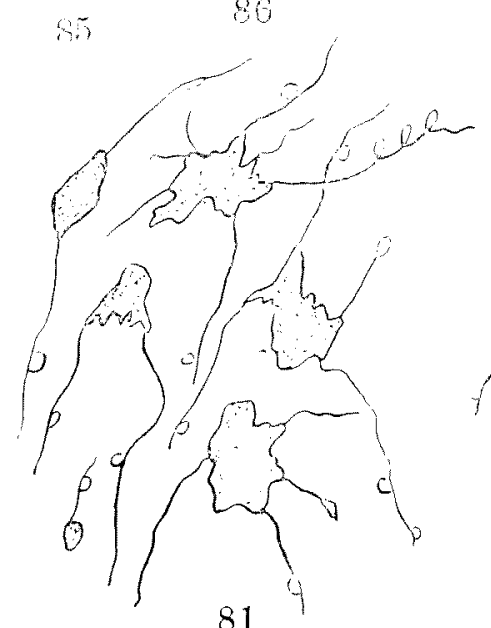

81

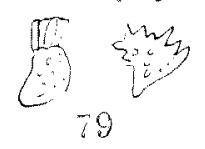

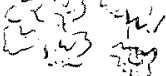

82

Fig. 79-84. Basiladia crassa (etwas schematisiert). ca. $645 \times$.

waren, aus. Die Figuren 84-86 zeigen Zoosporen 9 Stunden nach dem Zusatz von $10 \%$ igem Rohrzucker; die Objekte der Figuren 84 und 85 sind mit Zilien und Pseudopodien versehen, während das Objekt der Fig. 86 nur Pseudopodien allein aufweist.

Die Erklärung der übrigen Figuren möchte ich bei der Besprechung der Ergebnisse geben.

(Fortsetzung folgt) 